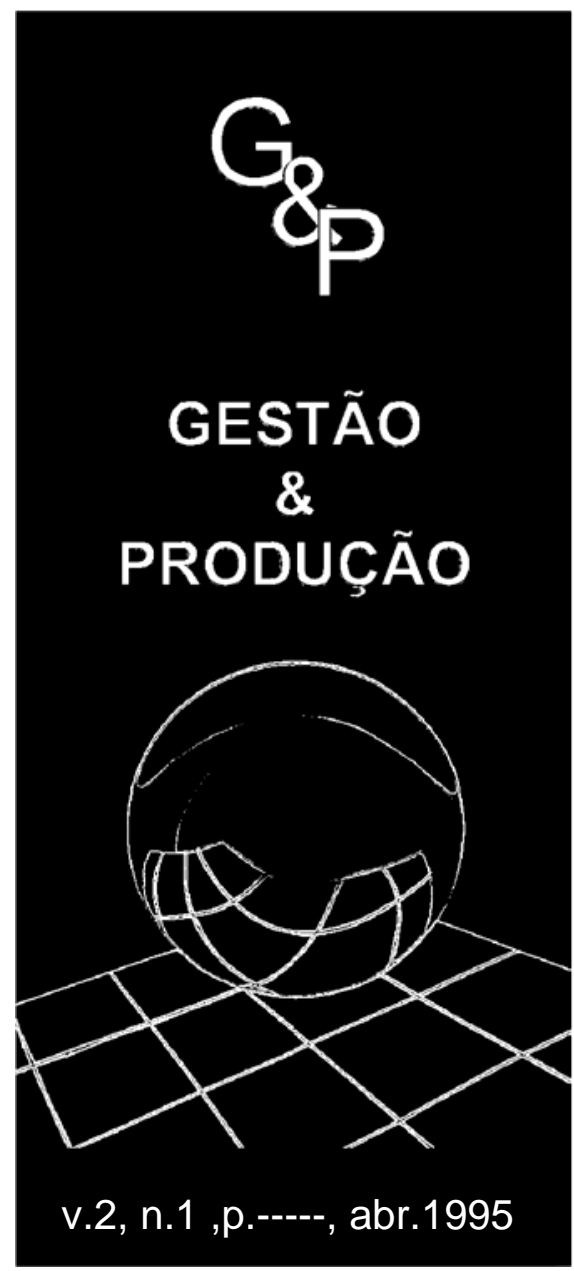

\title{
CONSIDERAÇÕES SOBRE O PLANEJAMENTO PARA A QUALIDADE DE SERVIÇOS E OS FATORES DE SUCESSO DE NOVOS EMPREENDIMENTOS
}

\author{
Tupanangyr Gomes Filho \\ Mestrando do Departamento de Engenharia de \\ Produção da E.P.U.S.P
}

Prof. Dr. Israel Brunstein

Professor Titular do Departamento de Engenharia de Produção da E.P.U.S.P.

\section{Resumo}

Propomos neste artigo destacar algumas ferramentas que contribuem para o desenvolvimento de pequenos e médios negócios no setor de serviços. Destacamos a metodologia para uma Estratégia de Operações como uma ferramenta de sobrevivência na prestação de serviços. O artigo abrange também o aspecto das características necessárias ao empreendedor de sucesso.

Palavras-chaves: Serviços, Operação de Serviço, Dimensões da Qualidade em Serviços, Áreas de Decisão em Serviço, Estratégia de Operações, Visão Estratégica em Serviços, Perfil Empreendedor, Perfil Gerente e Perfil Técnico .

\section{Introdução}

A Qualidade $e$ os Sistemas de Qualidade são fatores que internacionalmente vêm recebendo importante atenção, na medida em que, dentro do processo natural de concorrência, as empresas vêm buscando cada vez mais diferenciar suas linhas de produtos, seja ampliando a família de produtos, seja introduzindo inovações incrementais.

Por sua vez, o mercado consumidor torna-se cada vez mais exigente, demandando produtos e serviços com boa qualidade e que satisfaçam suas necessidades específicas . 
Segundo DRUCKER (1992), nos últimos cento e vinte anos a produtividade na indústria cresceu a uma taxa da ordem de $3 \%$ a $4 \%$ ao ano . Esse crescimento possibilitou grandes conquistas para a humanidade, dentre as quais: o aumento da renda disponível e do poder de compra; o acesso a serviços de saúde e educação; a melhoria da qualidade de vida. Os dados mostram que, no começo do século, qualquer trabalhador trabalhava no mínimo três mil horas por ano; em contrapartida, hoje, temos uma média de mil e oitocentas horas por ano nos Estados Unidos, duas mil horas no Japão e mil seicentos e cinqüenta na ex-Alemanha-ocidental (DRUCKER, 1992).

A revolução na produtividade dos setores primário e secundário já está superada, ou seja, a taxa de crescimento continuará da ordem de $3 \%$ a $4 \%$ ao ano, porém menos de um quinto da força de trabalho está deslocada para estes setores. Tomando o Japão como exemplo, observa-se que sua indústria ainda produz maciçamente, porém não se pode mais esperar incrementos de produtividade nessa área para justificar seu crescimento econômico. A grande maioria dos trabalhadores japoneses está no setor de serviços, porém a produtividade é tão baixa quanto em qualquer outro país desen-volvido.

O principal foco de atenção para países desenvolvidos e em desenvolvimento torna-se então o crescimento da produtividade e da eficiência do setor de Serviços, confor-me DRUCKER (1992) "O país que con-seguir primeiro alcançar esse objetivo dominará economicamente o século vin-te e um".

Conforme PORTER (1990), a necessidade crescente de serviços reflete vários fa-tores da sociedade atual:

- Maior riqueza.

- Desejo de melhor qualidade de vida.

- Mais tempo de lazer.

- Urbanização, tornando necessários alguns serviços novos (p.ex. serviços de segurança).
- Mudanças demográficas que aumentam o número de crianças e pessoas ido-sas que consomem muitos serviços.

- Mudanças sócio-econômicas, como famílias com duas carreiras profissionais, pressões sobre o tempo pessoal e menos atividades familiares conjun-tas, como refeições.

- Crescente sofisticação do comprador, que leva a exigências de serviços mais amplos e mais númerosos.

- Mudanças tecnológicas que aprimoram a qualidade do serviço ou tornaram possíveis serviços totalmente novos, como ocorre na assistência médica, televisão a cabo e bancos de dados ligados a computadores pessoais .

No Brasil podemos constatar que o setor de serviços representa 53\% do produto interno bruto, comparativamente a $66 \%$ do produto interno bruto, nos Estados Unidos (Anuário Estatístico do Brasil, 1991)

À medida que passarmos para uma economia mais desenvolvida teremos uma tendência de aumento dessa participação.

O crescimento das empresas prestadoras de serviços implica um problema cada vez mais comum: a falta de qualidade e de profissionalismo no setor.

Oportunidades e carreiras seguras ao abrigo das "intempéries" estão cada vez mais limitadas. Até mesmo os profissionais com boas qualificações encontram dificuldades, optando assim pelo setor de serviços, geralmente o chamado "negócio próprio", já que esta área é de mais fácil acesso, devido ao menor investimento inicial, se compararmos à indústria .

Esta opção pelo setor de serviços, caso feita de forma ordenada e profissional, acarreta bons ganhos quantitativos e qualitativos para a nação. Caso contrário acarreta muitas perdas para a sociedade, seja por serviços com baixo profissionalismo e qualidade, seja pela elevada rotação de negócios que fecham a cada ano, incorrendo em grandes perdas monetárias e sociais. 
Para os economistas os produtos são divididos em Tangíveis, conhecidos como Bens e Mercadorias, e Intangíveis, conhecidos como Serviços.

Observando-se um pouco mais a definição econômica de produto, podemos notar que nenhum produto é puramente tangível ou intangível. O que encontramos são com-binações em diferentes graus de Bens ou Mercadorias, Informações (Software) e Serviços (JURAN \& GRYNA, 1993), cada qual tendo uma participação maior ou menor no Produto.

Tabela 1 - Definição de Produto conforme JURAN \& GRYNA (1993)

\begin{tabular}{|c|c|}
\hline Bens ou Mercadorias & Material, Físico, Tangível \\
\hline $\begin{array}{c}\text { Informações ou } \\
\text { Softwares }\end{array}$ & $\begin{array}{c}\text { Informações, relatórios, processos lógicos para } \\
\text { execução de tarefas e manuais }\end{array}$ \\
\hline Serviço & Trabalho executado para terceiros \\
\hline
\end{tabular}

Serviço também pode ser definido como o conjunto das atividades (operações) de um Fornecedor na interface com um Clien- te, usuário ou comprador, com o objetivo de aumentar o valor de estado de uma pessoa ou objeto (WILD, 1977).

Tabela 2 - Valor de Estado e Serviço associado

\begin{tabular}{|c|c|}
\hline Valor de Estado & Serviço \\
\hline Transporte & Transportadora \\
\hline Beleza & Salão de Beleza \\
\hline Saúde & Hospital / Médico \\
\hline Alimentação & Fast-Food / Restaurantes \\
\hline Conhecimento & Escola / Universidade \\
\hline Corpo Físico & Acadêmias de Ginástica \\
\hline
\end{tabular}

No mercado encontramos produtos com maior grau de tangibilidade - Produto Mercadoria - e produtos com menor grau - Produto Serviço, ou simplesmente Serviços.

A tabela 3 dá-nos uma boa visão das diferenças entre uma mercadoria e um serviço. A intangibilidade do serviço dificulta ainda mais o controle da qualidade dos pro-cessos e produtos, devido ao relacionamento contínuo e próximo ao Cliente. Da mesma forma, as políticas de gerenciamento devem ser específicas .
Além dos fatores mencionados, podemos diferenciar algumas características de operação em relação às organizações centradas no Produto-Mercadoria e às organizações centradas no Produto-Serviço, conforme tabela comparativa 4

As características mencionadas na tabela 3 e 4 podem ser resumidas em quatro ca-racterísticas básicas, conforme tabela 5.

Tabela 3 - Produto Mercadoria e Serviço

\begin{tabular}{|c|c|}
\hline Produto Mercadoria & Produto Serviço \\
\hline Tangível & Intangível \\
\hline Estocável, Transportável & Perecível, Produção para atender a \\
& Demanda imediata \\
\hline
\end{tabular}


Compra, Consumo e Avaliação

separados
Compra, Consumo e Avaliação

simultâneas

Tabela 4 - Comparativo entre Operação Centrada em Mercadoria e Operação Centrada em Serviços ( Fonte: SCHWARTZ, 1991 )

\begin{tabular}{|c|c|c|}
\hline Operação Centrada no Produto Mercadoria & \multicolumn{1}{|c|}{ Operação Centrada no Produto Serviço } \\
\hline $\begin{array}{c}\text { O Cliente é pouco envolvido durante o } \\
\text { processo }\end{array}$ & $\begin{array}{l}\text { O Cliente está envolvido em muitas etapas do } \\
\text { processo }\end{array}$ \\
\hline $\begin{array}{c}\text { Produção, Venda, Distribuição e Consumo são } \\
\text { separados }\end{array}$ & $\begin{array}{l}\text { Produção, Venda, Distribuição e Consumo são } \\
\text { simultâneos, podendo constituir uma única etapa }\end{array}$ \\
\hline Produção é indepedente do Consumo-Estoques & $\begin{array}{l}\text { Produção é freqüentemente relacionada ao } \\
\text { Consumo }\end{array}$ \\
\hline $\begin{array}{c}\text { Projeto do Produto é centralizado no Cliente e } \\
\text { Projeto do Processo no Funcionário }\end{array}$ & $\begin{array}{l}\text { Projeto do Produto e Processo são } \\
\text { centralizados no Cliente }\end{array}$ \\
\hline Variabilidade na Produção é menor & Maior Variabilidade na Produção \\
\hline $\begin{array}{c}\text { Maior facilidade para medições, padrões, ins- } \\
\text { peções e amostragens }\end{array}$ & $\begin{array}{l}\text { Maior dificuldade para controlar, medir, padro- } \\
\text { nizar, inspecionar e amostrar o processo de pro- } \\
\text { dução - Processo "Just-in-Time" ao extremo }\end{array}$ \\
\hline Processo tecnicamente mais complexo & Menos complexo tecnicamente \\
\hline $\begin{array}{c}\text { Relacionamento Funcionário - Cliente } \\
\text { geralmen-te não é complexo nem crítico }\end{array}$ & $\begin{array}{l}\text { Relacionamento Funcionário - Cliente é com- } \\
\text { plexo e crítico para os resultados finais }\end{array}$ \\
\hline Conhecimento Teórico domina a operação & $\begin{array}{l}\text { Características extra-pessoais dominam a } \\
\text { operação }\end{array}$ \\
\hline Treinamento é mais físico & \begin{tabular}{l} 
Treinamento é mais psicológico e mental \\
\hline Quem produz não está em contato com o o
\end{tabular} & $\begin{array}{c}\text { Quem produz geralmente está em contato com } \\
\text { o Cliente }\end{array}$ \\
\hline Cliente & Economia de Escala é menor \\
\hline Economia de Escala é maior &
\end{tabular}

Tabela 5 - Quatro Características Básicas na Prestação de Serviços

\begin{tabular}{|l|l|}
\hline Característica & \multicolumn{1}{c|}{ Descrição } \\
\hline • Intangibilidade & $\begin{array}{l}\text { Serviços são muito menos tangíveis que mercadorias. Um comprador de } \\
\text { um produto mercadoria tem a oportunidade de ver, tocar, ouvir ou degustar } \\
\text { antes de decidir pela sua compra. O prestador de serviços deve enfatizar os } \\
\text { benefícios do sistema como um todo, ao invés do serviço como um produto } \\
\text { isolado. }\end{array}$ \\
\hline - Perecibilidade & $\begin{array}{l}\text { Serviços são perecíveis, não podem ser inventariados. Neste tipo de } \\
\text { operação a falta de estoques retira uma importante ferramenta de controle } \\
\text { do processo, que se caracteriza pelo estoque "pulmão", para amortecimento } \\
\text { das flutuações de demanda. Na indústria convencional o estoque de pro- } \\
\text { dutos acabados absorve flutuações da demanda, permitindo assim isola- } \\
\text { mento entre o ambiente externo e as diversas etapas de produção . }\end{array}$ \\
\hline •Heterogeneidade & $\begin{array}{l}\text { Segundo Henry Ford, "minha empresa podia produzir qualquer carro de } \\
\text { qualquer cor desde que do modelo T e da cor preta ". Encontramos na pres- } \\
\text { tação de serviços o oposto da afirmação do Sr Henry Ford. A presença do } \\
\text { cliente, associada à intangibilidade do serviço, implica uma grande varia- } \\
\text { bilidade no produto serviço, já que para cada cliente temos ou um produto } \\
\text { diferente ou um atendimento que se ajusta a cada necessidade do cliente. }\end{array}$ \\
\hline
\end{tabular}




\begin{tabular}{|l|l|}
\hline \multirow{3}{*}{ - Simultaneidade } & $\begin{array}{l}\text { A simultaneidade da produção e do consumo soma-se às restrições men- } \\
\text { cionadas pelas características acima. Controle de Qualidade do Produto } \\
\text { final deixa de ser uma função estática no tempo, para ter uma atuação em } \\
\text { todo o processo de produção. } \\
\text { A simultaneidade torna a falha ou erro um alvo para a perda de negócios } \\
\text { e conseqüentemente da rentabilidade da empresa. Devemos ter, mais do } \\
\text { que na manufatura, especial atenção com a qualidade na prestação de } \\
\text { serviço, já que o erro ou a falha são na maioria dos casos irrecuperáveis. }\end{array}$ \\
\hline
\end{tabular}

\section{Qualidade de Serviços e Competitividade}

Uma preocupação atual tanto no setor de serviços como na manufatura, reside em como projetar ou operar eficientemente os négocios, a fim de manter ou ganhar poder competitivo .

Em termos de operações em serviços, a vantagem competitiva de longo prazo refere-se largamente à qualidade do serviço prestado e ao seu processo de fornecimento (PORTER,1990).

Entretanto, como podemos definir Qualidade em Serviços ?

Qualidade é um tópico de crescente inte-resse no mundo dos negócios de hoje. $\mathrm{O}$ custo da baixa ou inconsistente qualidade e o valor da alta e consistente qualidade são colocados em evidência nas empresas e pa-ra os consumidores finais de produtos e serviços .

O mundo ocidental tem seu foco gerencial dirigido para a qualidade do produto, enquanto o mundo oriental se concentra na qualidade como uma filosofia para toda a organização. Neste contexto, identificamos qualidade como um modo de vida para toda a organização. Qualidade não somente interfere nos produtos ou serviços, mas nas receitas financeiras, na saúde e segurança dos funcionários, na estratégia, no gerenciamento, nas relações humanas e em todo processo produtivo e de prestação de serviços.

GIANESI \& CORRÊA (1993) combinaram as visões de vários autores e sugerem nove critérios para a avaliação da qualidade em serviços. Tais critérios criam condições para a avaliação dos aspectos envolvidos durante a prestação de serviços. Devido às características da prestação de um serviço, a definição dos critérios de qualidade torna-se bastante complexa, dado o grande número de variáveis envolvidas e controladas pelo consumidor durante 0 processo. Estas variáveis abrangem desde a velocidade de atendimento e conhecimento da operação do fornecedor até sua postura, apresentação visual e capacidade de comunicação . Na tabela 6 encontramos estes nove Critérios Competitivos em serviços .

Analogamente à manufatura, a empresa de serviços não consegue obter excelência em todos os critérios competitivos ao mesmo tempo, devido aos conflitos internos (trade-offs) existentes entre eles, como por exemplo: Custo versus Flexibilidade ou Ve-locidade de Atendimento versus Empatia/ Cortesia .

A necessidade de focalizar os atributos em que a empresa deve obter excelência implica a elaboração de uma Estratégia de Operações .

A ocorrência dos trade-offs requer que se estabeleça quais critérios competitivos são mais importantes, em função das neces-sidades e expectativas dos clientes e consu-midores do serviço, e relacionandoos às restrições e capacidades internas da empre-sa, as quais chamamos de Áreas de Decisão.

A Estratégia de Operações fica estabelecida pela ligação entre os Critérios Competitivos estabelecidos e as Áreas de Decisão, apresentadas na tabela 7 . 
Tabela 6 - Critérios Competitivos em Serviços

(Fonte: GIANESI \& CORRÊA, 1993)

\begin{tabular}{|c|c|}
\hline Critérios Competitivos & Descrição \\
\hline 1. Consistência & $\begin{array}{l}\text { - conformidade com o pré-estabelecido } \\
\text { • falta de variabilidade nas saídas dos processos; } \\
\text { - confiabilidade em relação a cada uma das operações nas } \\
\text { diversas etapas do serviço; } \\
\text { - "fazer certo da primeira vez". }\end{array}$ \\
\hline 2. Competência & $\begin{array}{l}\text { - conjunto de conhecimentos e habilidades necessárias } \\
\text { para se prestar o serviço; } \\
\text { - relativo às necessidades técnicas do consumidor. }\end{array}$ \\
\hline $\begin{array}{l}\text { 3. Velocidade de } \\
\text { Atendimento }\end{array}$ & $\begin{array}{l}\text { - tempo necessário para que a empresa e seus funcionários } \\
\text { possam prestar o serviço; } \\
\text { - refere-se ao tempo de espera (real ou percebido) em cada } \\
\text { uma das etapas da prestação de serviços . }\end{array}$ \\
\hline 4. Empatia /Atmosfera & $\begin{array}{l}\text { - prover atenção individualizada; } \\
\text { - cortesia ao atender o cliente; } \\
\text { • comunicação na linguagem do cliente; } \\
\text { • sensação de bem-estar; } \\
\text { - atmosfera /ambiente gerada pela empresa. }\end{array}$ \\
\hline 5. Flexibilidade & $\begin{array}{l}\text { - capacidade de variar e adaptar as operações de acordo } \\
\text { com as necessidades e expectativas dos clientes. }\end{array}$ \\
\hline $\begin{array}{l}\text { 6. Credibilidade / } \\
\text { Segurança }\end{array}$ & $\begin{array}{l}\text { - redução da percepção de risco, principalmente na } \\
\text { avaliação pré-compra mas também durante o processo; } \\
\text { - habilidade em gerar sensações de credibilidade e de } \\
\text { segurança }\end{array}$ \\
\hline 7. Acesso & $\begin{array}{l}\text { - localização conveniente; } \\
\text { - facilidade de aproximação e de contato; } \\
\text { - disponibilidade dos serviços; } \\
\text { - horas de funcionamento ( } 24 \text { horas; Domingos ). }\end{array}$ \\
\hline 8.Aspectos Tangíveis & $\begin{array}{l}\text { - qualidade e/ou aparência de qualquer evidência física } \\
\text { (bens facilitadores, equipamentos, instalações, ou até } \\
\text { mesmo outros consumidores ). }\end{array}$ \\
\hline 9. Custo & $\begin{array}{l}\text { - o preço deve estar numa faixa competitiva, tomando-se o } \\
\text { cuidado de lembrar que o preço do serviço muitas vezes } \\
\text { é usado pelo cliente como uma pista de avaliação do pré- } \\
\text { compra. }\end{array}$ \\
\hline
\end{tabular}


Tabela 7 - Áreas de Decisão. (Fonte: GIANESI \& CORRÊA, 1993)

\begin{tabular}{|c|c|}
\hline Áreas de Decisão & Decisões Relativas a \\
\hline 1. Projeto do Serviço & $\begin{array}{l}\text { - conteúdo do pacote de serviço; foco; velocidade de } \\
\text { atendimento; alavancagem de valor sobre custo . }\end{array}$ \\
\hline 2. Processo / Tecnologia & $\begin{array}{l}\text { - separação front-office e back-room; } \\
\text { - grau de contato com o consumidor (alto/baixo); } \\
\text { - equipamentos , automação e controle. }\end{array}$ \\
\hline 3. Instalações & $\begin{array}{l}\text { - localização, descentralização, layout, decoração e ma- } \\
\text { nutenção. }\end{array}$ \\
\hline 4. Capacidade / Demanda & $\begin{array}{l}\text { - dimensionamento da capacidade; } \\
\text { - ajustamento da demanda no tempo; } \\
\text { - nivelamento da relação capacidade/demanda. }\end{array}$ \\
\hline 5. Força de Trabalho & $\begin{array}{l}\text { - níveis de habilidade desejados; } \\
\text { • recrutamento seleção e treinamento de pessoal; } \\
\text { • políticas de renumeração (participação). }\end{array}$ \\
\hline 6. Qualidade & $\begin{array}{l}\text { - prevenção e recobrimento de falhas ; } \\
\text { - padrões de serviço. }\end{array}$ \\
\hline 7. Organização & $\begin{array}{l}\text { - grau de centralização da tomada de decisões; } \\
\text { - estilos de liderança, comunicação e autonomia de } \\
\text { deci-sões. }\end{array}$ \\
\hline 8. Administração de Filas & $\begin{array}{l}\text { - disciplina na fila; configuração da fila; tempo total } \\
\text { • gestão da percepção do cliente sobre o tempo de espera. }\end{array}$ \\
\hline 9. Sistemas de Informação & - coleta, análise e uso de informações. \\
\hline 10. Gestão de Materiais & $\begin{array}{l}\text { - Políticas de fornecimento, estoques, suprimento e } \\
\text { níveis de disponibilidade. }\end{array}$ \\
\hline 11. Gerenciamento do Cliente & $\begin{array}{l}\text { - participação e treinamento dos clientes; } \\
\text { • comunicação e monitoramento das expectativas . }\end{array}$ \\
\hline 12. Medidas de Desempenho & $\begin{array}{l}\text { - prioridades, padrões, métodos e medição de desem- } \\
\text { penhos que propiciem o controle das operações }\end{array}$ \\
\hline 13. Controle das Operações & - Programação de operações e regras de decisão. \\
\hline
\end{tabular}

Podemos observar em SARIAN (1993) o desenvolvimento de uma Estratégia de Operações voltada a uma loja de seguros.

No trabalho o autor identifica:

- Necessidades de Clientes: Competência dos Funcionários; Pagamento de Comissões; Bom Atendimento; Flexi-bilidade de Negociação; Pagamento de Indenizações; Informatização; Acesso;

- Critérios Competitivos mais importantes: 1.Consistência; 2.Competência; 3.Velocidade de Atendimento; 6.Credibilidade/Segurança; 7.Acesso.

- Áreas de Decisão Prioritárias: 2.Processo/Tecnologia; 3.Instalações;
4.Ca-pacidade/Demanda; 5.Força de Tra-balho; 6.Qualidade.

Vários autores pesquisados destacam a necessidade de se diferenciar a formulação de uma estratégia de operações para empresas de serviços, quando comparada à de uma empresa de manufatura, dadas as quatro características básicas na prestação de serviço mencionadas.

Autores como WELSCH (1983) e ANSOFF et al. (1981) identificam com muita perícia a atividade administrativa de planejamento estratégico das organizações. Seus trabalhos, porém, basicamente envolvem todas as atividades de um empreendimento industrial, voltado à empresa de manufatura e processos . 
HESKETT (1986) sugere o estudo estratégico para a implantação de novos negócios, no setor de serviços. Seu trabalho originou-se da observação de como operam empresas de serviços bem sucedidas no mundo, o que chamou de "Visão Estraté-gica de Serviços", que complementa o pro-cesso descrito da formulação de estratégia de operações.
Segundo o autor, a visão estratégica de serviços consiste na identificação de um segmento/mercado alvo, posicionando o serviço em relação à concorrência e seu mercado alvo, no desenvolvimento de serviços orientados a necessidades dos clientes, de uma estratégia de operações que irá direcionar o projeto e gestão de operação. Esses elementos básicos estão descritos na tabela 8 .

Tabela 8 - Visão Estratégica de Serviços (Adaptado de: HESKETT, 1986)

\begin{tabular}{|c|c|c|}
\hline $\begin{array}{c}\text { Segmento / } \\
\text { Mercado Alvo }\end{array}$ & ÜPosicionamentoP & Serviços \\
\hline $\begin{array}{l}\text { - Quais são as principais } \\
\text { características comuns do } \\
\text { segmento? } \\
\text { - Quais as dimensões que po- } \\
\text { dem ser usadas na seg- } \\
\text { mentação do mercado? } \\
\text { •Demográficas? } \\
\text { - Psicográficas? } \\
\text { - Que importância têm os vá- } \\
\text { rios segmentos? } \\
\text { - Que necessidades cada um } \\
\text { deles tem? } \\
\text { - Como cada um está sendo } \\
\text { atendido? } \\
\text { - De que maneira? } \\
\text { - Por quem? }\end{array}$ & $\begin{array}{l}\text { • Como o conceito de serviço } \\
\text { se propõe a atender as ne- } \\
\text { cessidades dos consumi- } \\
\text { dores ? } \\
\text { - Como os concorrentes aten- } \\
\text { dem estas necessidades? } \\
\text { - Como o serviço proposto é } \\
\text { diferenciado dos competi- } \\
\text { dores ? } \\
\text { - Quão são relevantes estas } \\
\text { diferenças ? } \\
\text { - O que é um "bom serviço } \\
\text { "? } \\
\text { - O serviço proposto é um } \\
\text { "bom serviço" ? } \\
\text { - Que esforços são neces- } \\
\text { sários para alinhar as ex- } \\
\text { pectativas dos consumido- } \\
\text { res e as capacitações do } \\
\text { serviço proposto ? }\end{array}$ & $\begin{array}{l}\text { - Quais são os elementos im- } \\
\text { portantes dos serviços for- } \\
\text { necidos, caracterizados em } \\
\text { termos de resultados pro- } \\
\text { duzidos para os clientes ? } \\
\text { - Como estes elementos são } \\
\text { percebidos por: } \\
\text { segmento alvo ? } \\
\text { mercado em geral ? } \\
\text { funcionários? } \\
\text { • Como os clientes percebem } \\
\text { o Serviço ? } \\
\text { - Que esforços são feitos pa- } \\
\text { ra a percepção do Serviço } \\
\text { em termos de : } \\
\text { Projeto? } \\
\text { Distribuição? } \\
\text { Comercialização ? }\end{array}$ \\
\hline
\end{tabular}

\section{Planejamento para a Qualidade de Serviços e Sobrevivência dos Negócios}

O setor de serviços, devido ao seu relativo baixo investimento, tem maior concentração de pequenos e médios negócios .

Conforme GERBER (1986), nos Estados Unidos anualmente encontramos 500.000 pessoas iniciando algum tipo de negócio. No final do primeiro ano, $40 \%$ estarão fora de seu negócio. Após cinco anos, mais de $80 \%$, ou seja, 400.000 pessoas falharão em seus negócios. No final dos cinco anos subseqüentes, somente $20 \%$, das que restaram, estarão no mercado .

No Brasil a situação se repete. Conforme pesquisa feita pelo SEBRAE-SP, em 
1992 cerca de um milhão de pessoas lançaram-se no mercado (430.665 empresas). Cerca de $50 \%$ não conseguiram passar do primeiro ano.

A rotação de negócios sensibiliza-nos para a falta de preparo adequado dos empresários, gerentes ou técnicos, que em determinado momento de suas vidas decidem pelo seu "negócio próprio".

Algumas conseqüências desta facilidade ficam claramentes evidentes na baixa consistência dos serviços prestados no Brasil. Algumas questões se fazem necessárias e nos levam ao questionamento das operações atuais.

- Por que a maioria dos pequenos negócios falha?
- Por que a maioria dos pequenos negócios que sobrevivem tem resultados abaixo do esperado ?

- Por que alguns pequenos empresários são dirigidos pelo seu negócio, fazendo o trabalho de seus funcionários?

- Por que alguns empresários trabalham arduamente para obter um discreto resultado?

A premissa fatal ilustrada por GERBER (1986) reside no claro entendimento de que o conhecimento técnico da operação não significa que se conheça o negócio que rea-liza a operação. Este mal entendido muitas vezes é a raiz para o fracasso de um empreendimento.

Identificamos, segundo GERBER (1986), três características inerentes ao perfil do "Empreendedor de Sucesso", conforme tabela 9.

Tabela 9 - Características inerentes ao Empreendedor de Sucesso

\begin{tabular}{|l|l|}
\hline Característica / Perfil & \multicolumn{1}{c|}{ Descrição } \\
\hline • Empreendedor & $\begin{array}{l}\text { • Este perfil gosta de estar no futuro, é a personalidade criativa. } \\
\text { Seu desejo é a mudança e se concentra/mantém controle nos } \\
\text { assuntos relativos às suas visões ( "Visão Interessada"). }\end{array}$ \\
\hline • Gerente & $\begin{array}{l}\text { - Ordena, planeja e prevê. Tenta minimizar os efeitos das va- } \\
\text { riáveis externas não controláveis. Este perfil identifica nas } \\
\text { mu-danças a raiz dos problemas. }\end{array}$ \\
\hline - Técnico & $\begin{array}{l}\text { Tue confiança no que pode fazer, não delegando e confiando } \\
\text { a-dia, é quem "põe a mão na massa". }\end{array}$ \\
\hline
\end{tabular}

Obviamente, existem conflitos entre as três características mencionadas. Muitas das idéias do Empreendedor não se ajustam ao mundo real, frustando tanto o Técnico co-mo o Gerente. O Gerente deseja reduzir tudo a um sistema e "congelar" mudanças que tanto incomodam o Técnico e o Em-preendedor.

A maioria dos negócios falham devido ao Técnico assumir o controle do negócio, da forma que o "dono" gostaria ao invés da que o negócio necessita. O Técnico ne- cessita de um local para ir trabalhar, estar livre para fazer o que quer, imune às mudanças ou restrições impostas pelo Empreendedor e pelo Gerente.

Os pequenos e médios negócios que no longo prazo têm sucesso são aqueles que têm claramente estabelecida uma Visão Estratégica Empreendedora, ao invés de ter o foco no trabalho diário. A estratégia empreendedora tem seu foco no que deve ser feito hoje para se atingir os objetivos futuros conforme tabela 10 . 
Tabela 10 -Visão Estratégica Empreendedora

\begin{tabular}{|c|c|}
\hline Visão Estratégica Empreendedora & Visão Técnica \\
\hline - Como meu negócio funciona. & - Qual trabalho precisa ser feito. \\
\hline $\begin{array}{l}\text { - O negócio é um sistema para produzir resul- } \\
\text { tados para Clientes. }\end{array}$ & $\begin{array}{l}\text { - O negócio e um local de trabalho } \\
\text { para gerar resultados internos . }\end{array}$ \\
\hline $\begin{array}{l}\text {-Procura de novas formas de satisfazer neces- } \\
\text { sidades dos clientes }\end{array}$ & -Satisfazer interesses próprios . \\
\hline $\begin{array}{l}\text { - Existência do curto, médio e longo prazos. } \\
\text { - Planejamento Estratégico de Operações. }\end{array}$ & $\begin{array}{l}\text { - Preocupação principal com o presente. } \\
\text { - "Fechar o Caixa" }\end{array}$ \\
\hline $\begin{array}{l}\text { - Visão do negócio como um entidade derivada } \\
\text { de suas partes( Integração). } \\
\text { O negócio é uma rede onde cada integrante } \\
\text { contribui para o resultado comum planejado. }\end{array}$ & $\begin{array}{l}\text { - Visão do negócio como uma série de } \\
\text { partes . }\end{array}$ \\
\hline
\end{tabular}

Uma das conseqüências da falta de uma Visão Estratégica Empreendedora é a relação entre o ciclo de vida do negócio e o entusiasmo do Empreendedor (NORMANN, 1991 e VOSS et al.,1988).

Durante os primeiros meses de vida, fase 1 do ciclo, em que a empresa recém inau-gurada está se tornando conhecida, o ne-gócio é operado basicamente no modo em-preendedor ("visão interessada" e o alto entusiasmo) .

Na fase 2 do ciclo (crescimento), o volume de negócios aumenta consideravelmen-te. A pressão da "produção", a necessidade de controle de custos e prazos, a super-visão das tarefas, aliada à "preferência do dono" para realizar algumas tarefas que lhe dão mais prazer, levam muitos Empreen-dedores a estarem mais envolvidos, como um Técnico.

Nesta etapa encontramos a "desilusão" em relação ao negócio, com muito trabalho para pouco resultado. O dilema entre continuar ou fechar ou vender a empresa passa a ser a principal preocupação. Encontramos nesta fase os $40 \%$ que " morrem " no primeiro ano de vida .

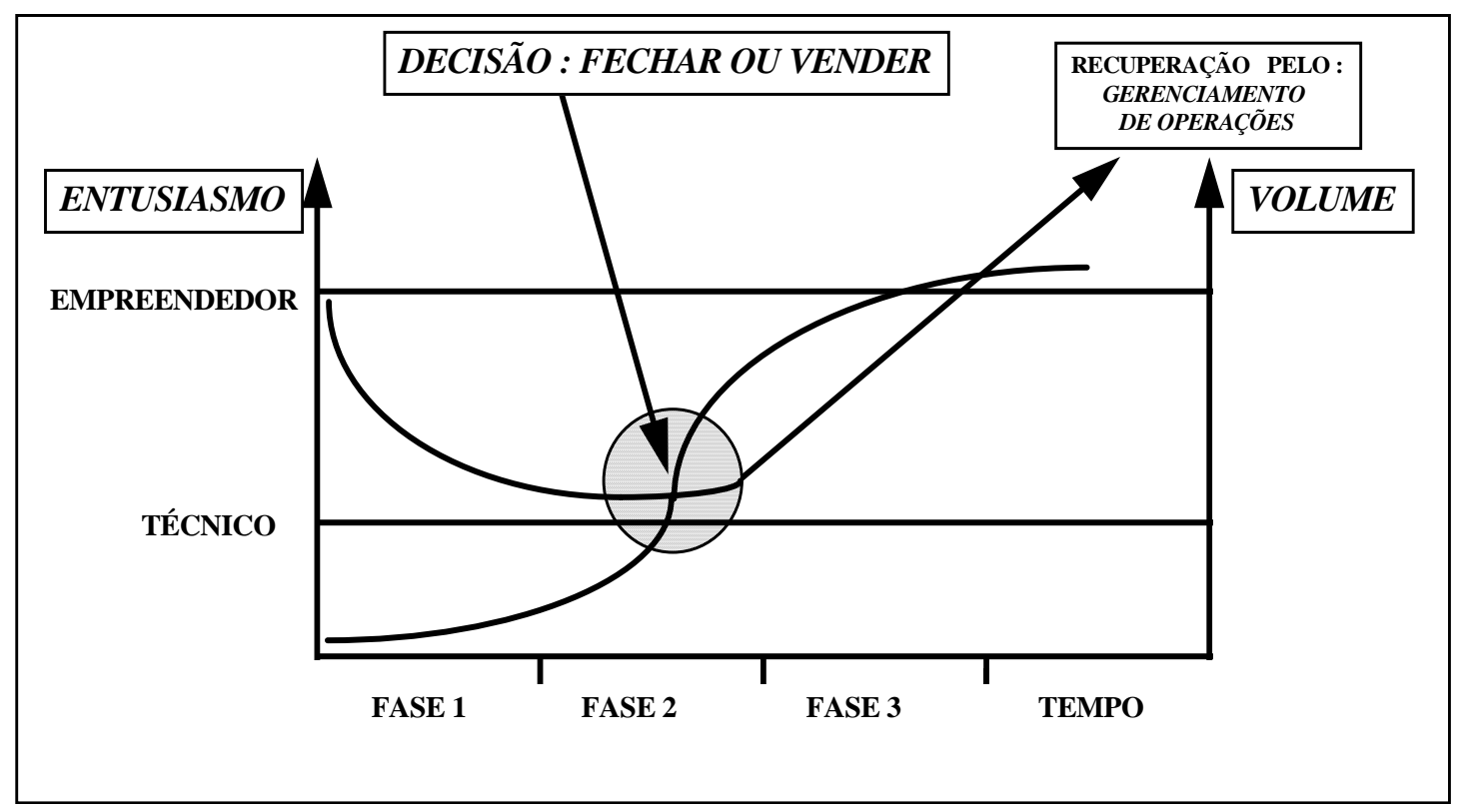


Figura 1 - Ciclo de Vida do Negócio

A solução para reduzir a "mortalidade infantil" de negócios reside no desenvolvimento de uma verdadeira gerência de operações, dirigida aos itens formulados na Estratégia de Operações.

Na terceira fase do ciclo (maturidade), o Empreendedor atinge sua maturidade, ou seja, o balanceamento entre as atividades do Empreendedor, do Gerente e do Técnico em perfeita harmonia, possibilitando ao ex-dono do negócio, agora empresário, olhar adiante para suas necessidades .

\section{5-Conclusão}

Encontramos neste artigo uma revisão da literatura relevante disponível sobre o setor de serviços, possibilitantando identifi-car aspectos peculiares à sua prestação.

Iniciamos pela definição das características básicas na prestação de serviços: intangibilidade; perecibilidade; heterogenei-dade e simultaneidade, passando a defini-ção de critérios competitivos para avaliação da qualidade no setor .

A ligação entre os critérios competitivos mais importantes e as áreas de decisão es-pecíficas do setor constitui o processo de formulação de uma Estratégia de Operações.
A proposta neste artigo é evidenciar que a qualidade no setor de serviços não está somente relacionada à formulação de uma Estratégia de Operações mas também a uma Visão Estratégica Empreendedora.

O sucesso de um negócio está intimamente ligado ao fornecimento ou desenvolvimento de um modelo de negócio robusto, que estimule a personalidade empreendedo-ra e derrube as barreiras da personalidade técnica.

Infelizmente o sonho do negócio próprio na maioria das vezes não leva em conta nenhuma estratégia de operações nem uma auto-avaliação no tocante às características pessoais necessárias .

\section{Referências Bibliográficas:}

ANSOFF, I.; DECLERK, R. \& HAYES, R.L.: Do planejamento Estratégico à Administração Estratégica. Editora Atlas, São Paulo ,1981 .

DRUCKER, P.: Artigo da Harvard Business Review públicado na Revista Exame, Edição 499 ano 24 No. 4 pag. 56, São Paulo, 1992 .

GERBER, E.M.: The Emyth, Why most businesses don't work and what to do about it. Harper Business, New York, 1986 .

GIANESI, I.G.N. \& CORRÊA, H.L.: "Contribution to Service Operation Strategy Development". In: Johnston,
R. \& Slack, N.D.C. (eds.): Service Superiority - The Design and Delivery of Effective Service Operations. Operations Management Association, Warnick, (pp 13-19), 1993.

HESKETT , J.L.: Managing in the Service Economy. Harvard Business School Press , Boston, 1986.

JURAN, J.M. \& GRYNA, F.M.: Controle da Qualidade Total Handbbok (volu-me VIII; 4a ed.). MacGraw Hill São Paulo, 1993.

NORMANN, R.: Service Management : Strategy and leadership in Service bu- 
siness (Cap. 10, pag. 115). John Wiley \& Sons ltd., New York, 1991.

PORTER, M.E.: The Competitive Advantage of Nations. Macmillan Press, London, 1990.

SARIAN, G.: Visão Estratégica de Serviços : Estudo de um Projeto Piloto para uma Loja de Atendimento aos Corretores de Seguros. Trabalho de Formatura apresentado ao Departamento de Engenharia de Produção da Escola Politécnica da U.S.P., EPUSP, São Paulo, 1993.
SCHWARTZ, M.H.: "...". Quality Progress, November 1991.

VOSS, C.; ARMISTEAD, C.; JOHNSTON, B. \& MORRIS, B.: "Operations Strategy " In: Operations Management in Service Industries and $\mathrm{Pu}-$ blic Sector (4th ed.), Cap. 11 pag. 269, John Wiley \& Sons , Chichester, 1988.

WELSCH : Orçamento Empresarial. Editora Atlas, São Paulo,1983.

WILD, R.: Concepts for Operations Management. John Wiley \& Sons, New York, 1977.

\section{PLANNING FOR QUALITY IN THE SERVICE AREA AND CRITICAL FACTORS FOR SUCCESS IN NEW ENTERPRISES}

\section{Abstract}

The authors suggest some tools to contribute to the development of small and medium businesses in the service sector. We call attention to the development of an Operation Strategy as a tool for survival in the business. The article also covers the personal character of the successful entrepreneur.

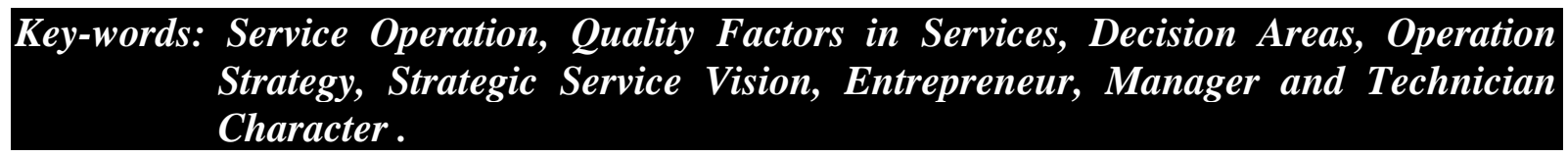

